\section{ALEXANDRE, O GRANDE, NA ALEXANDRA, DE LÍCOFRON}

Roosevelt Rocha*

Recebido em: 06/03/2020

Aprovado em: 29/03/2020

\begin{abstract}
RESUMO: Neste breve artigo farei um comentário detalhado dos versos 1435-45, da Alexandra, de Lícofron. Nesse poema, Cassandra, a filha do rei troiano Príamo e irmã de Páris Alexandre, faz uma série de profecias sobre o futuro de Troia e dos gregos que estão prestes a conquistar a cidade no momento em que ela profetiza. Dentre essas previsões, ela menciona rapidamente Alexandre, o Grande, que fará dormir os conflitos entre Ocidente e Oriente. O que pretendo fazer aqui é apresentar uma análise detalhada dos onze versos nos quais o conquistador macedônio é mencionado: com que metáforas e com que imagens ele é retratado, a que linhagens ele pertence e a que lugares ele é associado.
\end{abstract}

PALAVRAS-CHAVE: Alexandre, o Grande; Lícofron; Alexandra; metáforas; imagens.

\section{ALEXANDER THE GREAT, IN THE \\ ALEXANDRA, BY LYCOPHRON}

* Professor Associado, Departamento de Polonês, Alemão e Letras Clássicas, Universidade Federal do Paraná.

rooseveltrocha@yahoo.com.br

\begin{abstract}
In this brief paper I will make a detailed commentary on verses $1435-45$ of the Alexandra by Lycophron. In this poem, Cassandra, the daughter of the Trojan king Priam and sister of Paris Alexander, makes a series of prophecies about the future of Troy and the Greeks who are about to conquer the city as she prophesies. Among these predictions, she briefly mentions Alexander the Great, who will put to sleep the conflicts between West and East. What I intend to do here is to present a detailed analysis of the eleven verses in which the Macedonian conqueror is mentioned: with what metaphors and with what images he is portrayed, to which lineages he belongs and to which places he is associated.
\end{abstract}

KEYWORDS: Alexander the Great; Lycophron; Alexandra; metaphors; images. 
A Alexandra, atribuída a um certo Lícofron, é um poema do período helenístico, composto, provavelmente, na primeira metade do século II a.C. ${ }^{1}$ Nele, encontramos as profecias que um guarda ouviu Cassandra Alexandra, filha de Príamo, rei de Troia, proferir depois que seu pai mandou prendê-la para tentar conter sua fúria inspirada por Apolo. Nesse conjunto de profecias, ela prevê a destruição da sua cidade, fala do que aconteceria com os principais chefes da expedição aqueia, incluindo seus retornos, alguns fracassados, outros bem-sucedidos, como é o caso de Odisseu. Ela fala também do futuro do mundo grego, incluindo os conflitos com os persas e a ocupação macedônica, até a conquista romana, que aconteceria no século II a.C. Esse poema é uma importante fonte de narrativas míticas alternativas, ou seja, diferentes das versões que encontramos em Homero e Hesíodo, por exemplo, e é considerado um texto obscuro, por causa do seu estilo alusivo, carregado de metáforas e de linguagem simbólica.

Como até agora esse texto foi pouco estudado no mundo lusófono, ${ }^{2}$ apresento aqui um resumo um pouco mais detalhado, também para que o leitor tenha uma melhor noção da posição e da importância da alusão feita a Alexandre, o Grande, quase no final do poema. Ele começa com um prólogo proferido pelo guarda (do verso 1 ao 30), no qual ele explica qual é o estado de espírito de Cassandra, a qual é apresentada como uma mulher enfurecida por causa das visões proféticas que teve há pouco. Em seguida começa o discurso propriamente de Cassandra (do verso 31 ao 1460), no qual ela trata da primeira destruição de Troia, ${ }^{3}$ pelas mãos de Héracles (v. 31-51), e já faz a primeira menção à segunda queda de Troia, dessa vez causada pelos aqueus liderados por Agamêmnon (v. 52-6). Depois de falar de Enone, a primeira esposa de Páris, e da maneira como Dárdano escapou do dilúvio (v. 57-85), ela trata do rapto de Helena realizado por Páris, o qual o fez sem saber que, na verdade, estava levando uma espécie de fantasma, um simulacro, para Troia. ${ }^{4}$ A profetisa aproveita esse momento para falar dos cinco 'esposos' de Helena (v. 144-79): Teseu, Páris, Menelau, Deífobo e Aquiles (o qual ela desposaria depois de sua morte, já na ilha Branca,

\footnotetext{
${ }^{1}$ Hornblower (2015, p. 36-7), mais recentemente, propôs a hipótese de que o poema tenha sido escrito por volta do ano 190 a.C., data pouco posterior à vitória dos romanos, comandados por T. Quinctius Flamininus, sobre os macedônios, liderados por Filipe V, em Cinoscéfalas. Para outras propostas, ver Hurst e Kolde (2008, p. xxiii e ss.). Hornblower (2015, p. 26 e 36-41) defende, ainda, que o autor do poema seria um poeta do sul da Itália que viveu no século II a.C. Ele teria sido influenciado pelos poetas helenísticos mais conhecidos: Calímaco, Apolônio de Rodes, Teócrito e Eufórion.

${ }^{2}$ Recentemente foi publicada a primeira tradução completa em língua portuguesa de que tenho notícia, a de Vieira (2017). Já é uma grande contribuição, tendo em vista a enorme lacuna que representa a ausência de estudos sobre Lícofron em língua portuguesa. Porém, são necessários mais estudos e novas traduções acompanhadas de notas e comentários estendidos. Dois artigos já foram publicados por pesquisadores brasileiros sobre questões relacionadas ao poema: cf. Brunhara (2015) e Rocha (2008). ${ }^{3}$ É interessante observar aqui que Cassandra não menciona apenas acontecimentos futuros em relação àquele momento, mas também a eventos do passado que, de alguma maneira, têm relação com o que acontecerá mais tarde, anos ou séculos depois.

${ }^{4}$ Esse tema já tinha sido desenvolvido por Estesícoro (fr. 192 PMGF = 91a Finglass), Heródoto (2,112-120) e Eurípides (na tragédia intitulada Helena).
} 
que ficaria localizada na foz do rio Danúbio). Os aqueus, então, sacrificam Ifigênia, fazem juramentos e partem para Troia (v. 180-218). Depois de lamentar o fato de seu pai não ter dado crédito aos oráculos de Prílis e Ésaco (v. 219-28), Cassandra prevê a chegada dos aqueus em Tênedo, onde Aquiles matará Cicno e seus filhos (v. 229-42). Os gregos então desembarcam em Ílion, trazendo destruição e sofrimento, especialmente para a família dela: morte para Heitor, Troilo, Laodice e Polixena (seus irmãos e irmãs), e para sua mãe, Hécuba, e seu pai, Príamo, o qual permitiu a entrada do cavalo de madeira dentro das muralhas da cidade (v. 243-347). Na sequência, ela trata de um fato importante dentro da economia do poema: o estupro praticado por Ájax Oileu contra ela, que será a causa do sofrimento e da morte de muitos aqueus, quando eles tentarem retornar para seus lares (v. 348-416). A partir daí ela começa a tratar dos retornos (v. 417-1282), que ocupam boa parte do poema. Ela então revela onde Fênix, Calcas, Idomeneu, Estênelo, Mopso e Anfíloco serão enterrados (v. 417-46); cinco líderes, Teucro, Agapenor, Acamas, Cefeu e Práxandro, irão para Chipre, onde serão fundadores de cidades e serão cultuados como heróis (v. 447-591); Diomedes irá para a Dáunia, no leste da atual Itália (v. 592-632), e os beócios se fixarão nas ilhas Baleares (v. 633-47). A seguir, Cassandra trata das peripécias de Odisseu no seu longo percurso até chegar a Ítaca (v. 648-819), trecho já conhecido como a Odisseia de Lícofron. Cassandra trata também das errâncias de Menelau (v. 820-76), que passou pelo Egito (onde encontrou a verdadeira Helena), pela Sicilia e pela ilha de Elba. Rapidamente, ela fala também dos naufrágios sofridos pelos tessálios Guneu, Protoo e Eurípilo (v. 877-908). Neste momento, a narrativa apresenta uma breve pausa, e encontramos uma transição de caráter reflexivo e lamentoso:

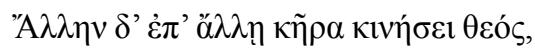

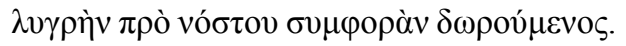
910

Uma desgraça após a outra um deus moverá, funesto infortúnio ao invés do retorno concedendo.

Na continuação, alguns personagens partirão para o oeste, Filoctetes para Crotona e Epeio para Lagária, no sul da Itália (v. 911-50); troianos fundarão cidades no oeste da Sicília (v. 951-77) e gregos colonizarão a baía de Tarento, Bruttium (atual Calábria), o norte da Lỉia e a Ilíria (noroeste dos Bálcãs), Malta, o Epiro, a Dáunia (região no leste da Itália, já citada antes, onde Diomedes seria cultuado como herói fundador) (v. 978-1074). Aqui Cassandra se dirige diretamente a uma escrava troiana chamada Setaia, e que teria ateado fogo nos barcos gregos que estavam ancorados na região de Síbaris e, por isso, foi crucificada (v. 1075-82). ${ }^{5}$ Em seguida, a filha de Príamo fala rapidamente dos gregos que colonizarão a Lucânia, no sul da Itália (v. 1083-6), e um sumário do que foi dito até aqui é apresentado (v. 1087-9):

\footnotetext{
${ }^{5}$ Esse tipo de apóstrofe acontece algumas vezes no poema, geralmente dirigindo-se a alguma personagem troiana. Cf. v. 31, 52, 69, 72, 90, 281 (dirigindo-se a um dáimon, uma divindade ou o Destino, tratado como uma divindade), 323, 348, 373-86, 815 (dirigindo-se excepcionalmente a Odisseu) e 968, 1146-51, 1174, 1189, 1452, por exemplo.
} 


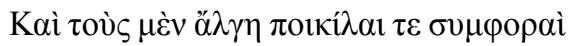

1087

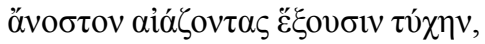

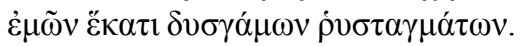

E dores e múltiplos infortúnios os

1087

terão, enquanto lamentam seu destino sem retorno,

por causa dos meus maus-tratos de más bodas.

Voltando ao fio da narrativa, mesmo aqueles que conseguirem chegar em casa sofrerão (v. 1090-8), como é o caso de Agamêmnon, que será assassinado junto com Cassandra (v. 1099-122). Contudo, Agamêmnon será cultuado em Esparta, e Cassandra, na Dáunia, no leste da Itália (v. 1123-40). Por causa da violência praticada por Ájax Oileu, que era da Lócrida, na Grécia, as mulheres da Lócrida Epizefíria, no sul da Itália, prestarão culto a Cassandra (v. 1141-73). Em seguida, o destino de Hécuba é anunciado (v. 1174-88), e também o culto que Heitor receberá em Tebas, na Beócia (v. 1189-213). Além de Odisseu e Agamêmnon, Idomeneu também enfrentará problemas ao retornar para sua casa, em Creta (v. 1214-35). E, ao tratar das errâncias de Eneias, Cassandra faz previsões também sobre a grandiosidade de Roma (v. 1236-80). Para encerrar esse longo trecho sobre os destinos dos heróis envolvidos na guerra de Troia, Lícofron nos apresenta uma terceira e última recapitulação (v. 1281-2):

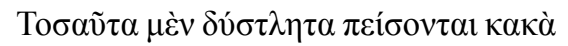

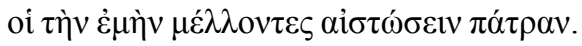

Tantos excruciantes males assim sofrerão os que estão prestes a destruir a minha pátria.

Os últimos versos do poema tratam essencialmente dos conflitos entre Europa e Ásia (v. 1283-450). Depois de uma introdução (v. 1283-90), Cassandra fala do rapto de Io (v. 1291-5), do rapto de Europa e de outras hostilidades praticadas por cretenses (v. 1296-308), da ida de Medeia com Jasão e os argonautas da Cólquida para a Grécia (v. 1309-21), e do rapto de Antíope, praticado por Teseu e Héracles, e da invasão da Ática pelas amazonas por causa disso (v. 1322-40). Depois disso, Ilo invade a Trácia e a Macedônia, Héracles saqueia Troia (v. 1341-50), e os lídios realizam conquistas na região central da Itália (v. 1351-61). Na sequência, Páris reacende a chama do conflito, e os Gregos praticam quatro agressões: a guerra de Troia, Orestes coloniza a Eólida (no noroeste da Ásia Menor), o ateniense Neleu funda Mileto, e gregos de origem dórica fundam colônias na Ásia Menor (v. 1362-96). Em reação, o rei Midas, da Frígia, invade a Trácia e a Macedônia, e Cassandra dá um grande salto de séculos para fazer referência à invasão persa, liderada por Xerxes, e sua derrota humilhante (v. 1397-434). A última profecia de Cassandra anuncia a vitória final de um parente dela que trará a conciliação entre os dois continentes (v. 1435-50). Ela então diz suas últimas palavras e cala-se (v. 1451-60). No epílogo, o guarda conclui seu relato para o rei Príamo (v. 1461-74), e assim termina o poema.

Retomando então nossa exposição, é importante lembrar que esse texto foi composto no período helenístico, num momento em que o personagem Alexandre, o Grande, já estava 
deixando de ser simplesmente um personagem histórico para se tornar um herói mítico, comparável a Aquiles ou Héracles. Por isso, dentro de um poema chamado Alexandra e que apresenta uma série de profecias sobre o futuro do mundo mediterrânio, desde a época da guerra de Troia até o período da conquista romana, seria necessário, no mínimo, mencionar o grande rei macedônio. Isso acontece entre os versos 1435 e 1445, onde é atribuído a Alexandre o papel de alguém que fará cessar o centenário conflito entre Ásia e Europa, que começou em tempos míticos com os raptos de Io e de Europa.

Aqui abaixo apresento o texto grego, de acordo com a edição de Hornblower (2015), e uma tradução não metrificada:

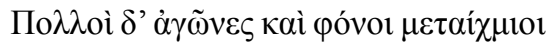
1435

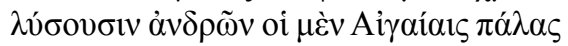

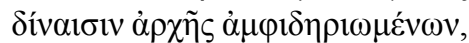

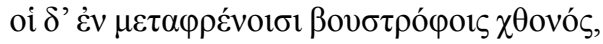

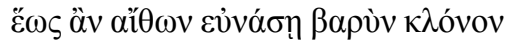

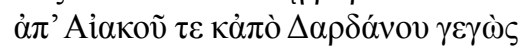
1440

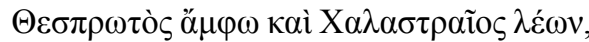

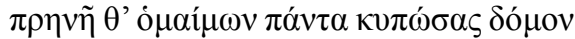

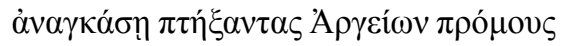

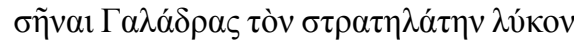

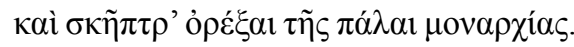

Muitas contendas e massacres entre dois exércitos resolverão lutas de homens, uns, que combatem desde o princípio nos abismos do Egeu, outros nos dorsos bovinarados da terra, até que um ardente leão de Éaco e de Dárdano nascido, tanto Tesproto quanto Calastreu, 1440 faça dormir a pesada tormenta e, toda em ruínas tendo deixado a casa dos irmãos, obrigue, tendo-os aterrorizado, os chefes dos argivos a abanar o rabo para o lobo comandante de Galadra e a entregar o cetro da antiga monarquia.

Deixando de lado os problemas da datação e da unidade de composição do poema, farei comentários aqui ao trecho citado, onde o poema trata do fim do conflito entre Europa e Ásia que será levado a cabo por um guerreiro que obrigará os chefes dos Argivos a se submeterem a ele. Esse trecho pode ser dividido em duas partes: v. 1435-8, onde várias lutas que opuseram os inimigos são evocadas; e v. 1439-45, que tratam dos grandes feitos do leão/lobo ou do leão e do lobo. Os versos 1435-8 dizem que muitas batalhas e guerras acontecerão, umas em terra e outras no mar, até o surgimento de um grande líder que porá fim a esses conflitos. É preciso observar que nos versos 1436-7 temos um problema

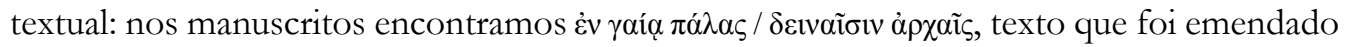
por alguns editores e cuja tradução seria algo como "em terra e em terra", resultado muito 
diferente da oposição esperada entre "na terra e no mar", que lemos no texto apresentado por Hornblower (2015, p. 493), que toma essa sugestão de Kaibel, defendida por Wilamowitz.

Sobre os versos 1439-45, a princípio, se não tivéssemos os escólios ${ }^{6}$ a essa passagem, não teríamos como saber quem seria esse leão/lobo. E, mesmo contando com os escólios, é preciso lembrar que ainda há propostas de alguns estudiosos que não identificam esses animais mencionados por Lícofron com o grande chefe macedônio, mas com outras personagens históricas do período helenístico. ${ }^{7}$

Segundo a hipótese mais aceita entre os comentadores, desde Tzetzes (poeta e gramático bizantino, que viveu no século XII), o leão e o lobo seriam a mesma personagem. ${ }^{8}$ E essa personagem só pode ser Alexandre: o próprio título do poema, a assimilação de Páris a Alexandre e a exaltação da obra pacificadora do filho de Filipe II reforçam essa hipótese. O leão é mencionado várias vezes no poema ${ }^{10} \mathrm{e}$ simboliza a coragem e a glória, e o epíteto aithon ${ }^{11}$ (cf. v. 246) qualifica o leão e outros animais quando são tratados de maneira metafórica. ${ }^{12}$ Além disso, os detalhes acerca da genealogia presentes no texto também reforçam essa interpretação. Entre os versos 1439 e 1441 ficamos sabendo ainda que os conflitos continuarão até que surja esse ardente (fogoso, corajoso) leão descendente de Éaco e de Dárdano, ou seja, alguém que tem sangue grego e troiano, europeu e asiático, ao mesmo tempo. Esse leão, de acordo com o verso 1440, é descendente de Éaco e Dárdano. Sabemos que Alexandre, por sua mãe, Olímpia, descende de Neoptólemo, filho de Aquiles, que era filho de Peleu e neto de Éaco, por sua vez. Por isso, Alexandre era um Eácida, como já indicam os escólios a esse verso. Recapitulando no outro sentido agora: Éaco era avô de Aquiles, que, por sua vez, foi pai de Neoptólemo, pai de Molosso, que se tornou rei do Epiro e foi antepassado de Olímpia, mãe de Alexandre. Dárdano foi avô de Heleno, terceiro marido de Andrômaca, depois da morte de Neoptólemo (cf. Teopompo 115 F 335 Jacoby). Olímpia seria descendente de Heleno também. Por isso, ao mesmo tempo, ele era descendente de Heleno,

\footnotetext{
${ }^{6}$ Para os escólios à Alexandra, cf. Leone (2002).

${ }^{7}$ Sobre isso, ver Hurst; Kolde (2008, p. xxii).

${ }^{8}$ Cf. v. 208-9, 445-55 e 553-8, para perceber a frequência da iteração em Lícofron. Ver também Mahé-Simon (2009, p. 443).

${ }^{9}$ No caso de Páris, o nome Alexandros é irônico, pois ele significaria algo como 'aquele que protege do homem' ou 'aquele que afasta o homem', e Páris não protegeu sua cidade nem afastou os homens dela. Mas é importante lembrar que um Alexandre foi um dos causadores dos conflitos entre Europa e Ásia, e outro Alexandre contribuirá para o fim desses conflitos.

${ }^{10}$ Cf. o léxico de Ciani (1975).

11 Aithon é usado no poema para qualificar diversos animais usados como metáforas para heróis. Cf. v. 246, 530, 925 e 1258. Talvez seja uma alusão à cor da pele de Alexandre. Cf. Plutarco, Vida de Alexandre, 4, 3 e Hurst; Kolde (2008, p. 314).

${ }^{12}$ É importante lembrar aqui que o leão é um animal intimamente associado a Héracles: veja-se o verso 33, onde o filho de Alcmena é chamado de 'leão de três noites', porque Zeus teria alongado o período em que estava com a mãe do herói para que ele fosse muito mais forte do que um homem normal. Héracles é chamado de 'leão’ também nos versos 459, 697 e 917.
} 
filho de Príamo, que era filho de Dárdano. Assim, Alexandre era também um Dardânida. Ou seja, ele tinha origens europeias, ocidentais, por ter sangue aqueu, e asiáticas, orientais, por ter sangue troiano também. Por essa razão, ele seria o líder destinado a dar fim ou pelo menos a dar uma pausa aos conflitos entre os dois continentes com a sua vitória na batalha de Gaugamela, em 331 a.C. Além disso, o verso 1441 indica que o leão era tesproto, já que, por sua mãe, Alexandre pertencia à linhagem dos soberanos do Epiro, reino onde ficava a região da Tesprótia. Por outro lado, o leão é também de Calastra, cidade da Macedônia onde ficava o lago Calastra e à qual estava ligada a família de seu pai, Filipe II.

Os versos 1441-45 podem ser interpretados da seguinte maneira: Alexandre destruirá a 'casa do mesmo sangue', porque vencerá os persas, ditos descendentes do argivo Perseu (Heródoto, 7, 61, 3), por exemplo. Por outro lado, os versos, 1441-42, podem conter uma alusão à destruição da Grécia, ou mais especificamente ao episódio da destruição de Tebas e, em seguida, podem estar tratando da unificação da Hélade ao mencionar o jugo imposto pelos macedônios aos argivos, que teriam o mesmo 'sangue', ou seja, as mesmas origens que os macedônios. ${ }^{13}$

A identificação do lobo, entretanto, é um pouco mais complexa. Os escólios já apontam para a identificação do leão e do lobo com Alexandre, o Grande, tendo em vista que Galadra é também uma cidade da Macedônia. É importante lembrar também que, no verso 102, Páris Alexandre é chamado de 'lobo'. Mahé-Simon (2009, p. 444-5) julga ser difícil admitir que a mesma personagem seja identificada com o leão e o com o lobo ao mesmo tempo. Há outras passagens em que uma mesma personagem é identificada com dois animais, ${ }^{14}$ mas isso acontece a partir de pares gêmeos. Na passagem examinada aqui, os animais não formam uma dupla desse tipo. Desse modo, seria necessário encontrar identificações diferentes para o leão e o lobo. Mahé-Simon (2009, p. 446-7) defende que o lobo seria Alexandre Molosso, tio de Alexandre, o Grande. Para aceitar essa hipótese seria necessário adotar a lição do codex Parisinus 2403 para o verso 1444 e substituir Galadra por Khaladra, nome de uma cidade do Epiro que passou a fazer parte do reino dos molossos na época de Alexandre. Sistakou (2009, p. 251-2, n. 42), contudo, mostra que seria possível um mesmo herói ser identificado metaforicamente com mais de um animal. Héracles, por exemplo, é identificado como leão e como lobo (v. 871-3), como acontece com Alexandre. Acredito ser importante observar também que, entre os versos 801 e 804, Lícofron menciona o assassinato de Héracles, filho de Alexandre com Barsine. ${ }^{15}$ Ele é o único personagem histórico cujo nome é citado sem o uso de metáforas ou simbolismos. Isso reforça a hipótese da aproximação entre Alexandre e o Héracles mítico e avaliza a ideia de que o grande general macedônio poderia, sim, ser representado metaforicamente por dois animais.

\footnotetext{
${ }^{13}$ Cf. Gigante Lanzara (2000, p. 430); Lambin (2005, p. 203); Chauvin e Cusset (2008, p. 158) e Hurst e Kolde (2008, p. xx-xxiii e 312-16). Para interpretações diferentes desses versos, conferir Mair (1921, p. 309-12).

${ }^{14}$ Cf. versos 445-55, 553-8, 1163-64 e 1178-80.

${ }^{15}$ Sobre isso, ver Hornblower (2015, p. 314-15).
} 
Concluindo, então, esta breve contribuição, pode parecer pequeno o espaço e a atenção dedicados a Alexandre, o Grande, dentro de um poema que faz importantes previsões sobre o futuro do mundo grego. Isso talvez possa ser justificado pelo privilégio dado a temas ocidentais ligados à Itália e pelo foco no futuro que reabilitaria os troianos com a conquista romana. Porém, acredito que não é ocioso frisar o papel determinante que Alexandre assume ao dar um primeiro passo no sentido da pacificação do mundo antigo, sendo o primeiro personagem que tem os pré-requisitos para ser bem sucedido nessa tarefa, por causa da sua dupla descendência europeia e asiática. É importante destacar também que a vitória final dos romanos será garantida por esse fato também, já que os romanos teriam, assim como Alexandre, origens orientais (troianas, através de Eneias) e ocidentais. Desse modo, portanto, podemos dizer que o processo de mitificação do grande conquistador macedônio já pode ser detectado na Alexandra, atribuída a Lícofron, poema composto, seja como for, no período helenístico, num momento historicamente ainda muito próximo do tempo de vida do personagem, no qual, certamente, a memória dos grandes feitos dele ainda estava muito viva.

\section{REFERÊNCIAS}

BRUNHARA, Rafael. A "seção romana" da Alexandra, de Lícofron (vv. 1226-1280). Cadernos de Literatura em Tradução, n. 15, 2015, p. 57-68. Disponível em: http://www.revistas.usp.br/ clt/article/view/114369.

CHAUVIN, Cédric; CUSSET, Christophe. Lycophron, Alexandra. Texte établi, trad., présenté et annoté. Paris: Harmattan, 2008. (Études grecques).

CIANI, Maria Gracia. Lexikon zu Lycophron. Hildesheim: Olms, 1975. (Alpha-Omega A22).

CLÚA I SERENA, Josep Antoni. Licófron de Calcis, Alexandra. Text revisat i trad. Barcelona: Fundació Bernat Metge, 1996. (Col·lecció catalana dels clàssics grecs i llatins, 298).

GIGANTE LANZARA, Valeria. Licofrone, Alessandra. Introduzione, traduzione e note. Milano: Biblioteca Universale Rizzoli, 2000. (BUR 1332 / RCS Libri).

HORNBLOWER, Simon. Lycophron. Alexandra. Greek text, Translation, Commentary, and Introduction. Oxford: Oxford University Press, 2015.

HURST, André; KOLDE, Antje. Lycophron, Alexandra. Texte établi, traduit et annoté par A. H. en collaboration avec A. K. Paris: Les Belles Lettres, 2008. (Collection des Universités de France, série grecque, 468).

LAMBIN, Gérard. L'Alexandra de Lycophron. Étude et traduction. Rennes: Presses Universitaires de Rennes, 2005. (Interférences).

LEONE, Pietro Luigi. Scholia vetera etparaphrases in Lycophronis Alexandram. Galatina: Congedo, 2002. 
MAHÉ-SIMON, Mathilde. Les deux Alexandre dans l'Alexandra de Lycophron. In: CUSSET, Christophe; PRIOUX, Évelyne (ed.). Lycophron: éclats d' obscurité. Actes du colloque international de Lyon et Saint-Étienne 18-20 janvier 2007. Saint-Étienne: Publications de l'Université de Saint-Étienne, 2009. (Mémoires du Centre Jean Palerne 33), p. 441-450.

MAIR, Alexander W. Callimachus, Hymns and Epigrams. Aratus, Phaenomena. Lycophron, Alexandra. Edited with a translation. Cambridge, MA: Harvard UP, 1921. (Loeb Classical Library, 129).

MCNELIS, Charles; SENS, Alexander. The Alexandra of Lycophron. A Literary Study. Oxford: Oxford University Press, 2016.

ROCHA, Roosevelt. A influência da tragédia na Alexandra, de Lícofron, e a questão da performance. Letras Clássicas, n. 12, p. 187-199, 2008.

DOI: https://doi.org/10.11606/issn.2358-3150.v0i12p187-199

SISTAKOU, Evina. Breaking the name code in Lycophron's Alexandra. In: CUSSET, Christophe; PRIOUX, Évelyne (ed.). Lycophron: éclats d'obscurité. Actes du colloque international de Lyon et Saint-Étienne 18-20 janvier 2007. Saint-Étienne: Publications de l'Université de Saint-Étienne, 2009. (Mémoires du Centre Jean Palerne, 33), p. 237-258.

VIEIRA, Trajano. Licofron. Alexandra. Tradução, apresentação e notas de Trajano Vieira. São Paulo: Editora 34, 2017. 